\title{
Extração de oleuropeína a partir de folhas de oliveira utilizando solvente hidroalcoólico
}

\author{
Extraction of oleuropein from olive leaves using a hydroalcoholic solvent
}

\section{Carolina Fernanda Sengling Cebin Coppa', Roice Eliana Rosim¹, Carlos Augusto Fernandes de Oliveira', Christianne Elisabete da Costa Rodrigues ${ }^{1}$, Cintia Bernardo Gonçalves ${ }^{1 *}$}

Universidade de São Paulo (USP), Faculdade de Zootecnia e Engenharia de Alimentos, Departamento de Engenharia de Alimentos, Pirassununga/ $S P$ - Brasil

\section{*Corresponding Author}

Cintia Bernardo Gonçalves, Universidade de São Paulo (USP), Faculdade de Zootecnia e Engenharia de Alimentos, Departamento de Engenharia de Alimentos, Campus Pirassununga, Av. Duque de Caxias Norte, 225, Caixa Postal: 23, CEP: 13635-900, Pirassununga/SP - Brasil, e-mail: cintiabg@usp.br

Cite as: Extraction of oleuropein from olive leaves using a hydroalcoholic solvente. Braz. J. Food Technol., v. 20, e2016169, 2017.

Received: Dec. 01, 2016; Accepted: June 09, 2017

\section{Resumo}

Folhas de oliveira contêm oleuropeína, um composto fenólico conhecido por seu potencial antioxidante, antimicrobiano, anti-inflamatório, entre outros. Este trabalho teve como objetivo estudar a extração da oleuropeína, utilizando solvente hidroalcoólico. Folhas de oliveira (FO) foram maceradas a $25^{\circ} \mathrm{C}$ com um solvente (S), formado por uma mistura de etanol e água (70:30 v/v), nas proporções FO:S iguais a 1:8, 1:6 e 1:3, em massa, com ou sem a presença de ácido acético. Observou-se que o maior teor de oleuropeína no extrato liofilizado ( $18 \mathrm{~g} / 100 \mathrm{~g}$, aproximadamente) foi obtido no procedimento utilizando a razão $\mathrm{FO}: S=1: 3$, com ácido acético. Por fim, foi realizado um teste para verificar o efeito do extrato liofilizado sobre o tempo de indução em amostras de azeite de oliva extravirgem e refinado, verificando-se um aumento de três e duas horas, respectivamente. Concluiu-se que é possível obter extratos de folhas de oliveira utilizando solventes renováveis e que a oleuropeína pode atuar como um antioxidante natural no azeite, melhorando sua estabilidade oxidativa.

Palavras-chave: Oleuropeína; Solvente hidroalcoólico; Maceração; Estabilidade oxidativa.

\section{Abstract}

Olive leaves contain oleuropein, a substance known for its antioxidant, antimicrobial and antiinflammatory potentials, amongst others. The objective of this work was to study the extraction of oleuropein using a hydroalcoholic solvent. Olive leaves (OL) were macerated at $25^{\circ} \mathrm{C}$ with a solvent (S) consisting of a mixture of ethanol and water $(70: 30 \mathrm{v} / \mathrm{v})$, with OL:S mass ratios equal to $1: 8,1: 6$ and $1: 3$, with or without the presence of acetic acid. The highest oleuropein content found in the freeze dried extract (approximately $18 \mathrm{~g} / 100 \mathrm{~g}$ ) was obtained from the procedure using an OL:S ratio $=1: 3$, in the presence of acetic acid. Finally, a test was carried out to verify the effect of the freeze dried extract on the induction time in samples of extra-virgin and refined olive oil, and increases of 3 and 2 hours, respectively, were observed. It was concluded that it is possible to obtain olive leaf extracts using renewable solvents, and that oleuropein can act as a natural antioxidant in olive oil, improving its oxidative stability.

Keywords: Oleuropein; Hydroalcoholic solvent; Maceration; Oxidative stability.

\section{Introdução}

A oleuropeína é um glicosídeo amargo, presente em todas as partes da árvore da oliveira, mas principalmente nas folhas. Vários estudos indicam que este composto fenólico possui importantes propriedades anti-inflamatórias (VISIOLI et al., 1998), antimicrobianas (TRIPOLI et al., 2005), antivirais (MICOL et al., 2005), entre outras. Sua capacidade de atuar como um antioxidante natural também tem atraído a atenção de pesquisadores, uma vez que os consumidores procuram cada vez mais produtos naturais ou que contenham componentes naturais em sua formulação, levando a indústria a pensar em substituir os antioxidantes sintéticos pelos extraídos de fontes vegetais (MOSCA et al., 2013). 
A escolha do método de extração é considerada uma das etapas mais críticas das pesquisas envolvendo produtos naturais. A eficiência do processo depende de diversos parâmetros, tais como o tipo de amostra e a substância a ser extraída e a sua localização no material vegetal (MUSTAFA; TURNER, 2011), além do tipo de solvente (XYNOS et al., 2012) e da temperatura da extração (GALANAKIS et al., 2010).

A maceração é um dos métodos mais utilizados para a obtenção de compostos fenólicos, a partir de fontes vegetais. Este é considerado um processo simples, uma vez que emprega o aquecimento e/ou agitação, a fim de alcançar a dissolução das substâncias presentes na amostra sólida para o solvente extrator (LUQUE DE CASTRO; GARCÍA-AYUSO, 1998; LUQUE DE CASTRO; PRIEGO-CAPOTE, 2010). A literatura tem relatado alguns estudos que envolvem a extração da oleuropeína utilizando-se o método de maceração simples (JIMENEZ et al., 2011; SAHIN et al., 2011) ou o método de maceração assistida por ultrassom ou micro-ondas (XIE et al., 2013; ACHAT et al., 2012; TAAMALLI et al., 2012; JAPÓN-LUJÁN et al., 2006a,b). Jimenez et al. (2011) estudaram a obtenção de extratos a partir folhas de oliveira secas, moídas e pré-escaldadas em água quente, e maceradas em etanol e água (1:1), por 24 horas, à temperatura ambiente, obtendo-se extratos hidroalcoólicos com 29\% de oleuropeína. Sahin et al. (2011) estudaram processos de extração de compostos fenólicos a partir de fontes vegetais, por meio de Soxhlet, tendo sido avaliados vários tipos de solventes [hexano, água, metanol, etanol e a mistura de metanol/hexano (3:2, v/v)], com um rendimento de oleuropeína de $37,84 \mathrm{mg} / \mathrm{g}$ de folha seca, para a condição, utilizando o metanol como solvente. Xie et al. (2013) constataram que as melhores condições para a extração de oleuropeína foram obtidas utilizando-se etanol 75\% (v/v), temperatura de extração igual a $50{ }^{\circ} \mathrm{C}, 600 \mathrm{~W}$ de energia do ultrassom, tempo de extração de três minutos, proporção líquido/sólido igual a 30:1 (mL/g) e pressão de extração igual a $25 \mathrm{kPa}$. Tais condições proporcionaram um rendimento total de oleuropeína de $(7,67 \pm 0,02) \%$, após três extrações. Em um estudo conduzido por Japón-Luján et al. (2006b), realizou-se a extração da oleuropeína das folhas de oliva utilizando a técnica de micro-ondas, em uma mistura de etanol e água (80:20, v/v), obtendo-se, assim, um teor igual a 2,3\% do composto. Taamalli et al. (2012) avaliaram a extração de compostos fenólicos das folhas de oliveira com o auxílio de micro-ondas à temperatura de $80^{\circ} \mathrm{C}$, durante seis minutos, utilizando-se uma mistura de metanol:água (80:20, v/v) como solvente da extração, o que resultou em um rendimento final de $16,7 \%$ para os compostos fenólicos. A extração com fluido supercrítico (TABERA et al., 2004; XYNOS et al., 2012) e a extração com fluido pressurizado (LOZANO-SÁNCHEZ et al., 2014) também foram descritas como métodos potenciais para obter oleuropeína das folhas de oliveira.
Utilizando-se condições experimentais diferentes das já adotadas na literatura, este trabalho visou ao estudo da obtenção de extratos de folha de oliveira contendo oleuropeína, empregando um solvente seguro e renovável (etanol + água), em diferentes proporções folhas:solvente, com ou sem a presença de ácido acético, além do estudo do efeito desses extratos sobre a estabilidade oxidativa de azeites comerciais.

\section{Material e métodos}

\subsection{Caracterização da matéria-prima}

As folhas de oliveira em pó (Olea europaea) foram adquiridas na empresa Chá e Cia ${ }^{\circledR}$ Ervas Medicinais (Jacareí, São Paulo, Brasil). O solvente utilizado foi uma solução hidroalcoólica preparada através da adição de água deionizada (Milli-Q, Millipore) ao etanol anidro (Merck, Darmstadt, Alemanha, pureza $\geq 99,9 \%$ ). A proporção mássica etanol/água utilizada foi de 70:30, otimizada em um trabalho prévio, no qual também se sugeriu o acréscimo de cerca de $1 \%$ de ácido acético na mistura, a fim de estabilizar a molécula de oleuropeína (PACETTA, 2013). O conteúdo de água no solvente foi checado em um densímetro digital (modelo DMA4500, da Anton Paar, Áustria) durante o período experimental, a fim de se garantir a proporção planejada.

As folhas de oliveira em pó foram caracterizadas em relação à sua composição química e ao teor de oleuropeína. Para a determinação da composição química (cinzas, lipídios, proteínas, fibra bruta e umidade) foram utilizados os métodos oficiais da AOAC (HORWITZ, 2005a,b,c,d), sendo que todas as análises foram realizadas em triplicata.

A quantificação da oleuropeína nas folhas em pó foi realizada seguindo a metodologia descrita por Altinyay e Altun (2006). Em um béquer, foram adicionados aproximadamente cinco gramas das folhas (pesadas em balança analítica, Adam) e $50 \mathrm{~mL}$ de metanol (Merck, Darmstadt, Germany, pureza 99,9\%). Com o auxílio de um agitador magnético (Tecnal), este sistema permaneceu sob agitação por um período de duas horas, à temperatura ambiente $\left(25^{\circ} \mathrm{C}\right)$. Após este período, foi realizada a filtração do sistema em filtros de papel $n^{\circ} 1$ (Whatman), sendo o filtrado (coletado em um béquer) submetido à evaporação em estufa sob vácuo (Tecnal), nas condições de $40{ }^{\circ} \mathrm{C}$ e $600 \mathrm{mmHg}$. O resíduo remanescente no filtro foi armazenado para uma posterior extração, com novo solvente. Em seguida, a amostra seca remanescente no béquer foi dissolvida em $50 \mathrm{~mL}$ de metanol (Merck, Darmstadt, Germany, pureza 99,9\%) e a solução formada foi filtrada em seringas contendo filtros (Allcrom), com tamanho de poros igual a 0,45 $\mu \mathrm{m}$. Um volume de $20 \mu \mathrm{L}$ desse extrato metanólico foi injetado em um equipamento de cromatografia líquida de alta eficiência (CLAE) (Shimadzu, modelo SPD-10A, Japão), acoplado a um detector de UV de $280 \mathrm{~nm}$, com uma taxa de fluxo de 1,0 mL/minuto, 
coluna Shimadzu CLC-ODS $25 \mathrm{~cm}$, controlador Shimadzu SCL-10AVP e amostrador automático SIL-10AF. A fase móvel consistiu de água + ácido fosfórico 0,1\% e metanol (Merck, Darmstadt, Germany, purity 99.9\%). A curva de calibração foi desenvolvida utilizando oleuropeína padrão (Sigma-Aldrich, St. Louis, pureza $>80 \%, \mathrm{MO}$, USA) e o programa LabSolutions (Versão 5:57, 2008-2013 Shimadzu Corporation). Para verificar se o resíduo sólido remanescente no filtro ainda continha oleuropeína, este foi submetido a um novo contato com o metanol, seguindo-se o mesmo procedimento descrito anteriormente e analisando-se cada extrato separadamente. Este procedimento foi repetido quatro vezes, porém apenas dois contatos com o solvente foram necessários para o esgotamento da oleuropeína das folhas de oliveira.

Azeites extravirgem e refinados (marca Gallo) foram adquiridos em um supermercado local e foram caracterizados em relação à composição de ácidos graxos, de acordo com os métodos oficiais Ce 1-62 e Ce 2-66 (FIRESTONE, 1998), e à acidez livre (PAQUOT, 1979).

\subsection{Procedimento de extração da oleuropeína}

Os experimentos para a obtenção dos extratos de folhas de oliveira foram realizados à temperatura ambiente $\left(25^{\circ} \mathrm{C}\right)$ e sob agitação magnética, variando a relação de folhas de oliveira (FO)/solvente ( $\mathrm{S}$ ) nos seguintes valores: 1:3 (10 g de folhas de oliveira em pó + $30 \mathrm{~g}$ de solvente), 1:6 (5 g de folhas de oliveira em pó $+30 \mathrm{~g}$ de solvente) e 1:8 (5 g de folhas e oliveira em pó + $40 \mathrm{~g}$ de solvente). Cada proporção foi estudada em triplicata, com e sem a adição de 1\% em massa de ácido acético (Synth, Diadema, Brasil, pureza > 99\%) em cada mistura.

As extrações foram realizadas no interior de recipientes de vidro Pyrex encamisados, mantidos sob agitação magnética durante duas horas. Após o período de extração, as amostras foram filtradas em papel filtro $\mathrm{n}^{\circ} 1$ (Whatman), sendo o extrato alcoólico colocado em um béquer de $50 \mathrm{~mL}$ e conduzido a uma estufa a vácuo a $40{ }^{\circ} \mathrm{C}$ e $600 \mathrm{mmHg}$, para a evaporação do etanol até peso constante. Após a evaporação, foram adicionados $20 \mathrm{~mL}$ de água deionizada aos béqueres, seguindo para o congelamento e a liofilização (liofilizador de bancada, LC Terroni), para a remoção da água restante, obtendo-se então o extrato liofilizado.

Um experimento adicional, chamado "extração sequencial", foi realizado para verificar o número de contatos com o solvente que seria necessário para maximizar o teor de oleuropeína no extrato liofilizado. Este experimento foi realizado em triplicata, à temperatura ambiente $\left(25^{\circ} \mathrm{C}\right)$, sob agitação constante por duas horas, utilizando a razão mássica FO/S igual a 1:3 (10 g de folhas de oliveira em pó $+30 \mathrm{~g}$ de solvente hidroalcoólico) e a adição de 1\% de ácido acético P.A. O procedimento para a obtenção do extrato liofilizado foi o mesmo descrito anteriormente, porém, após a primeira extração, o resíduo sólido restante no papel filtro foi conduzido a uma estufa de convecção forçada (Nova Orgânica) a $60^{\circ} \mathrm{C}$, para remover o solvente aderido, para que o material pudesse ser utilizado como matéria-prima na extração seguinte, com solvente novo. Este procedimento foi realizado em duplicata e foram executadas quatro extrações sequenciais, sempre mantendo a proporção FO/S igual a 1:3 pré-estabelecida.

Os quatro extratos liofilizados foram analisados individualmente em relação ao conteúdo de oleuropeína, através de cromatografia líquida de alta eficiência (CLAE), seguindo a metodologia descrita por Altinyay e Altun (2006). Cerca de $0,040 \mathrm{~g}$ do extrato liofilizado foi adicionado a um tubo de polipropileno de $15 \mathrm{~mL}$, misturando-o com uma solução de $1 \mathrm{~mL}$ de metanol (grau CLAE) + água deionizada (razão, em volume, 1:1). Este sistema permaneceu sob agitação durante 36 minutos em banho de ultrassom (Unique) e, em seguida, foi conduzido a uma centrífuga (Thermo Electron Corporation) a $25^{\circ} \mathrm{C}$ por 10 minutos, e rotação de $4.500 \mathrm{rpm}$. O sobrenadante foi recolhido e filtrado em seringas contendo filtros (Allcrom) com tamanho de poros igual a $0,45 \mu \mathrm{m}$, e transferido para um frasco (tipo vial) para análise em CLAE. A quantificação da oleuropeína na alíquota filtrada foi realizada utilizando o mesmo procedimento já descrito para as análises das folhas de oliveira.

\subsection{Efeito da aplicação dos extratos liofilizados em azeites de oliva}

Entre todos os extratos liofilizados obtidos nos experimentos descritos acima (exceto para o experimento de extração sequencial), o extrato contendo o maior conteúdo de oleuropeína foi selecionado para utilização nos azeites, a fim de verificar o seu efeito sobre a estabilidade oxidativa destes óleos, avaliada pelos tempos de indução. Para a realização da análise de estabilidade oxidativa, aproximadamente três gramas de azeite foram pesados em um tubo de polipropileno de $50 \mathrm{~mL}$, juntamente com $0,0015 \mathrm{~g}$ de extrato liofilizado [valores baseados na metodologia descrita por Jimenez et al. (2011)]. Para uma melhor solubilização do azeite e do extrato liofilizado, o tubo foi mantido sob agitação em um agitador de tubos (Ika) durante uma hora e, em seguida, cada tubo foi envolvido em folha de alumínio e embalado ao abrigo da luz e ao oxigênio, até a data da análise. Também foram executados experimentos adicionando-se o dobro do extrato liofilizado nas amostras de azeites (isto é, cerca de 0,0030 $\mathrm{g}$ de extrato), utilizando o mesmo processo descrito acima, a fim de se avaliar o efeito da concentração de oleuropeína na estabilidade oxidativa dos mesmos.

As análises de estabilidade oxidativa foram realizadas no aparelho Metrohm 873 Biodiesel Rancimat, pré-aquecido a $110^{\circ} \mathrm{C}$ e com fluxo de gás de $20 \mathrm{~L} / \mathrm{hora}$, sendo as análises realizadas em duplicata e levando-se em 
consideração que os resultados dos tempos de indução foram expressos em horas.

Os resultados foram comparados com os tempos de indução obtidos para amostras de azeite sem a adição de extratos liofilizados.

\subsection{Análises estatísticas}

Todos os resultados obtidos a partir dos experimentos de extração da oleuropeína, bem como os de estabilidade oxidativa dos azeites, foram analisados estatisticamente utilizando o Teste de Duncan em nível de confiança de $95 \%$, por meio do programa SAS ${ }^{\circledR}$ (Versão 9.3, SAS Institute Inc EUA).

\section{Resultados e discussão}

\subsection{Experimentos de extração da oleuropeína}

A Tabela 1 apresenta a composição química das folhas de oliveira em pó utilizadas no experimento de extração da oleuropeína. Estes resultados também foram comparados com os obtidos por Erbay e Icier (2009), para folhas frescas, e por Pacetta (2013), para folhas secas.

Erbay e Icier (2009) relataram a composição química das folhas de oliveira frescas, colhidas de árvores cultivadas no campus da Universidade de Ege, na Turquia. Os resultados encontrados pelos autores demonstraram que a composição de fibras e proteína bruta, e o conteúdo de umidade são muito semelhantes às amostras utilizadas no presente trabalho. No entanto, o conteúdo de cinzas e lipídios foi bastante diferente. Pacetta (2013) determinou níveis de cinzas e umidade de folhas de oliveira em pó cultivadas em Estiva Gerbi, São Paulo, Brasil. Quando comparados com os dados obtidos neste trabalho, este autor obteve quase o dobro do teor de umidade e o conteúdo similar de cinzas, o que pode ser explicado pela grande variabilidade que os materiais vegetais podem ter, dependendo de sua origem.

Seguindo a metodologia descrita por Altinyay e Altun (2006), o conteúdo de oleuropeína encontrado nas folhas de oliveira em pó foi igual a $(6,59 \pm 0,03) \mathrm{g}$ de oleuropeína/100 g de folhas secas. Como descrito anteriormente na seção 2.1, quatro extrações sequenciais com metanol foram realizadas, mas somente duas extrações foram necessárias para extrair toda a oleuropeína presente nas folhas de oliveira em pó (aproximadamente 93\% do total de oleuropeína contida nas folhas foram extraídas na primeira etapa e 7\%, na segunda etapa). Este conteúdo de oleuropeína é condizente com alguns estudos relatados na literatura, que indicam valores no intervalo $(2,3-17,95)$ $\mathrm{g}$ de oleuropeína/100 $\mathrm{g}$ de folhas secas (AOUIDI et al., 2012). No trabalho descrito por Xie et al. (2013), os autores conseguiram extrair cerca de $7,67 \%$ de oleuropeína das folhas de oliveira secas utilizando ultrassom e pressão reduzida, à temperatura de $50{ }^{\circ} \mathrm{C}$, concentração de etanol a $75 \%$ (v/v) e tempo de extração de três minutos. Japón-Luján et al. (2006a) obtiveram 2,30\% de oleuropeína por meio de extração dinâmica assistida por ultrassom, à temperatura de $40^{\circ} \mathrm{C}$, mistura de etanol e água 1:1 e tempo de extração de 25 minutos. Já Jimenez et al. (2011) extraíram $29 \%$ do conteúdo de oleuropeína das folhas de oliveira, através da maceração à temperatura ambiente, porém em um período de extração de 24 horas. Em outro estudo publicado por Stamatopoulos et al. (2014), os autores realizaram a extração da oleuropeína de folhas de oliveira secas utilizando o método de branqueamento a vapor em múltiplos estágios, por 30 minutos a $40^{\circ} \mathrm{C}$, e relação de solvente e água 70:30. Estas condições resultaram em um conteúdo de 0,46 g de oleuropeína/100 g de peso seco.

A Tabela 2 apresenta os resultados para a extração de oleuropeína por meio de maceração com etanol + água. Os resultados foram expressos em termos de rendimento de oleuropeína (RO) (Equação 1), conteúdo de oleuropeína nos extratos liofilizados (TO) (obtido por análise em CLAE) e rendimento global de extrato (RG) (Equação 2):

$$
\begin{aligned}
& \text { RO }(\%)=100 \times \frac{\text { massa de oleuropeína no extrato liofilizado }}{\text { massa de oleuropeína nas folhas de oliva }} \\
& \text { RG }(\%)=100 \times \frac{\text { massa de extrato liofilizado }}{\text { massa de folhas de oliva }}
\end{aligned}
$$

A partir dos resultados apresentados na Tabela 2, verificou-se que a presença de ácido acético atuou positivamente sobre o rendimento de oleuropeína $(\mathrm{RO})$ nas folhas de oliveira, para as razões de massa/solvente (FO/S) iguais a 1:3 e 1:6. No entanto, para a maior quantidade de solvente utilizado (proporção FO/S igual a 1:8), o valor de RO foi maior sem a presença do ácido no procedimento, sendo que todos os resultados dessa

Tabela 1. Composição centesimal das folhas de oliveira em pó.

\begin{tabular}{ccc}
\hline Componente & Conteúdo $\mathbf{( g / 1 0 0 ~ g ) ~}$ & Literatura (g/100 g) \\
\hline Umidade & $4,82 \pm 0,06$ & $49,83^{1} ; 8,3^{2}$ \\
Cinzas $^{*}$ & $11,89 \pm 0,02$ & $7,19^{1} ; 5,8^{2}$ \\
Fibra* & $14,55 \pm 0,30$ & $13,95^{1}$ \\
Lipídios $^{*}$ & $3,70 \pm 0,10$ & $13,03^{1}$ \\
Proteína $^{*}$ & $10,85 \pm 0,10$ & $10,86^{1}$ \\
Carboidratos* $^{*}$ & $59,00 \pm 0,34$ & $54,96^{1}$ \\
\hline
\end{tabular}

*Em base seca; ${ }^{\star *}$ Obtido por diferença (em base seca); ${ }^{1}$ Erbay e Icier (2009); ${ }^{2}$ Pacetta (2013). 
Tabela 2. Rendimento de oleuropeína (RO), teor de oleuropeína (TO) e rendimento global de extrato (RG), para o procedimento de extração por maceração.

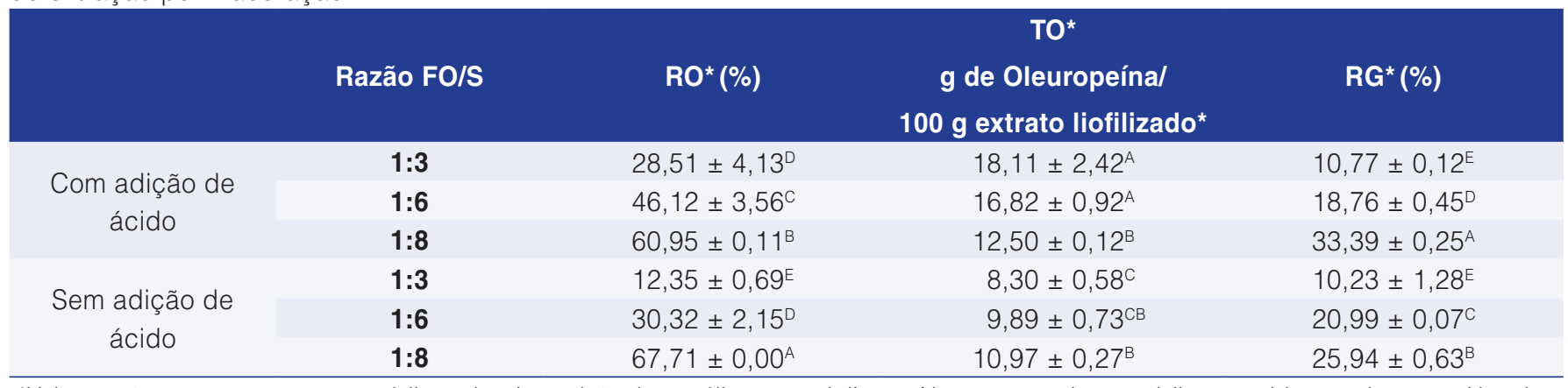

*Valores são expressos como a média \pm desvio padrão das análises em triplicata. Na mesma coluna, médias seguidas por letras maiúsculas iguais não diferem entre si no nível de $5 \%$ de significância, pelo Teste de Duncan. FO: folha de oliveira; S: solvente.

resposta diferiram entre si estatisticamente. Para a resposta teor de oleuropeína nos extratos (TO), também se observou a influência positiva da presença do ácido em todas as razões FO/S; porém, na razão 1:8, os valores de TO (com e sem ácido) não diferiram estatisticamente entre si. Em relação aos rendimentos globais de extrato (RG), estes também foram um pouco maiores nos experimentos realizados na presença de ácido (exceto para FO/S igual a 1:6), mas não houve diferença estatística entre os valores de FO/S na razão 1:3.

Pode-se observar também na Tabela 2 que, tanto para os procedimentos com ácido como para os sem ácido, o aumento da quantidade de solvente na extração conduziu ao aumento do rendimento de oleuropeína $(\mathrm{RO})$. Este resultado já era esperado, pois quanto maior a quantidade de solvente, maior quantidade de soluto este será capaz de solubilizar.

Em relação ao teor de oleuropeína nos extratos, notou-se que, para os experimentos com ácido, quanto maior a quantidade de solvente, menor o teor de oleuropeína (TO). De fato, os valores de TO estão relacionados aos valores de rendimento global (RG). Quando uma quantidade maior de solvente foi utilizada, extraiu-se mais oleuropeína, mas também se extraíram outros compostos, originando uma massa maior de extrato (maior rendimento). Como os valores de TO são obtidos pela massa de oleuropeína no extrato (obtida por manipulação dos resultados de CLAE) dividida pela massa total de extrato, era de se esperar o comportamento observado neste caso. Para os experimentos sem ácido, o inverso foi observado nos valores de TO, porém com pouca diferença significativa entre si.

Mkaouar et al. (2015) realizaram um estudo para verificar as condições de extração de compostos fenólicos das folhas de oliveira, avaliando parâmetros, como concentração do solvente, temperatura, proporção sólido:líquido e tempo de extração de três horas, através da técnica de DIC (do francês "Détente instantanée Contrôlée" - queda de pressão instantânea controlada), a qual sujeita a matéria-prima a um curto período de tempo em um vapor saturado, seguido de uma repentina queda de pressão de vácuo, induzindo assim à expansão do material vegetal, tornando-as mais aptas à transferência de massa. Os resultados foram analisados em Ultra Performance Liquid Chromatography (UPLC) e os autores verificaram que a variável que mais influenciou no rendimento dos polifenóis foi a concentração do etanol, com a temperatura e a relação folha:solvente apresentando poucas diferenças significativas. O efeito positivo do etanol está relacionado possivelmente com a alta afinidade dos compostos fenólicos presentes nas folhas com o solvente. Nos extratos das folhas de oliveira, o composto majoritário encontrado foi a oleuropeína (cerca de 90,31\%), seguido de outros, como verbascosídeo, hidroxitirosol, tirosol e ácido vanílico. As melhores condições encontradas para a extração dos compostos foi $95,59 \%$ de etanol a $55^{\circ} \mathrm{C}$. De acordo com esses autores, outros fatores, como natureza do solvente e o tempo de extração também podem levar a diferentes rendimentos dos compostos fenólicos.

Bilgin e Sahin (2013) também estudaram a extração de compostos fenólicos das folhas de oliveira, mas utilizando o metanol como solvente, em técnicas, como a homogeneização e a extração por ultrassom. Os autores encontraram melhores resultados - sendo o teor de fenólicos totais expresso em equivalentes de ácido gálico (GAE) por gramas de folhas secas - para o rendimento dos extratos fenólicos com a técnica de homogeneização, com valores entre 102,27 a 443,16 mg/g (10,11 - 61,66 mg GAE/g de folha seca), enquanto que, para o ultrassom, o teor variou entre 88,75 e 350,82 mg/g (7,35 - 38,66 mg GAE/g de folha seca). Vale ressaltar que, apesar de algumas pesquisas apontarem o metanol como um bom solvente para extrair a oleuropeína (fato que justifica sua utilização na metodologia de quantificação do composto), este possui alta toxicidade e pode comprometer a utilização dos extratos em alimentos.

Avaliando-se os resultados apresentados na Tabela 2, selecionou-se a relação $\mathrm{FO} / \mathrm{S}$ igual a 1:3, na 
Extração de oleuropeína a partir de folhas de oliveira utilizando solvente hidroalcoólico

Coppa, C. F. S. C. et al.

presença de ácido acético, para a realização de uma extração sequencial (total de quatro etapas), sempre se adicionando solvente novo em cada etapa. Optou-se por esta condição, pois esta requer uma menor quantidade de solvente e proporciona a produção de um extrato com o maior teor de oleuropeína (TO), apesar de também ter fornecido os menores valores de RO e RG, em comparação com as razões 1:6 e 1:8. Os resultados obtidos em cada estágio da extração sequencial estão demonstrados na Tabela 3.

De acordo com os resultados apresentados na Tabela 3, verificou-se que a oleuropeína permanece nas folhas de oliveira mesmo após quatro extrações sequenciais. Observou-se também que os valores de $\mathrm{RO}$, TO e RG diminuíram a cada etapa de extração, mostrando que estes dependem do teor inicial de oleuropeína na matéria-prima. Vale ressaltar que o cálculo da massa de oleuropeína na matéria-prima utilizada na segunda etapa de extração foi realizado através de balanço de massa, utilizando-se o valor conhecido do teor original do composto nas folhas de oliveira e o teor quantificado no extrato proveniente da primeira extração. O mesmo procedimento foi adotado para o cálculo da massa de oleuropeína presente nas folhas usadas nas terceira e quarta etapas da extração.

\subsection{Experimentos de estabilidade oxidativa}

A Tabela 4 apresenta a composição em ácidos graxos dos azeites de oliva utilizados no estudo de estabilidade oxidativa.
Avaliando-se o perfil de ácidos graxos nos azeites de oliva extravirgem e comum, há a presença de altos níveis de insaturação, demonstrando que estes óleos vegetais são vulneráveis à oxidação. Este fato reforça a importância de se estudar a adição de antioxidantes naturais, sem afetar sua composição química e nutricional, aumentando, assim, sua estabilidade oxidativa. As composições apresentadas na Tabela 4 estão de acordo com as normas internacionais para azeite de oliva (IOOC, 2015).

Em relação à acidez livre, o azeite refinado apresentou $(0,86 \pm 0,01) \mathrm{g} / 100 \mathrm{~g}$ e o azeite extravirgem apresentou $(0,56 \pm 0,01) \mathrm{g} / 100 \mathrm{~g}$, uma vez que ambos os valores são expressos em ácido oleico. De acordo com a Instrução Normativa $n^{\circ} 1$ de 30/01/2012 do MAPA (BRASIL, 2012), o azeite de oliva extravirgem não deve possuir acidez, expressa em ácido oleico, superior a 0,8 g/100 g, e o azeite de oliva refinado, acidez não superior a 0,3 g/100 g de azeite.

Massas conhecidas de extrato proveniente do processo utilizando a razão FO/S = 1:3 na presença de ácido (contendo aproximadamente $18 \mathrm{~g}$ de oleuropeína/100 g de extrato liofilizado), foram adicionadas em amostras de azeite, de modo a proporcionar uma quantidade de composto ativo dentro do intervalo utilizado em testes semelhantes aos descritos por Jimenez et al. (2011).

A Tabela 5 apresenta os tempos de indução obtidos para os óleos em três condições: (1) sem adição dos extratos de folhas de oliveira; (2) com adição dos extratos de folhas de oliveira; (3) com adição do dobro da massa de extrato utilizada na condição (2). O período de indução pode ser definido como o tempo necessário para

Tabela 3. Rendimento de oleuropeína $(R O)$, teor de oleuropeína (TO) e rendimento global de extrato (RG), para o procedimento de extração sequencial por maceração.

\begin{tabular}{ccrr} 
Etapa de extração & $\mathbf{R O}$ (\%) & $\begin{array}{c}\text { TO* } \mathbf{g} \text { de Oleuropeína/100 } \mathbf{g} \\
\text { extrato seco* }\end{array}$ & $\mathbf{R G *}^{*}(\%)$ \\
\hline 1 & $38,11 \pm 3,09$ & $16,77 \pm 1,76$ & $15,58 \pm 0,37$ \\
2 & $12,55 \pm 1,25$ & $13,87 \pm 1,40$ & $6,20 \pm 0,01$ \\
4 & $6,32 \pm 0,77$ & $10,04 \pm 3,24$ & $4,45 \pm 0,91$ \\
\hline
\end{tabular}

*Valores são expressos como a média \pm desvio padrão das análises em triplicata.

Tabela 4. Composição em ácidos graxos dos azeites de oliva.

\begin{tabular}{|c|c|c|c|}
\hline \multirow{2}{*}{$\begin{array}{c}\text { Ácido graxo } \\
\left(C \times y^{\star}\right)\end{array}$} & \multicolumn{2}{|c|}{ Azeite de oliva } & \multirow{2}{*}{ Literatura** } \\
\hline & Extravirgem & Comum & \\
\hline Palmítico (C16:0) & $11,60 \pm 0,13$ & $14,14 \pm 1,01$ & 7,50 a 20,00 \\
\hline Palmitoleico (C16:1) & $0,82 \pm 0,03$ & $3,83 \pm 0,54$ & 0,30 a 3,50 \\
\hline Esteárico (C18:0) & $2,74 \pm 0,05$ & $2,46 \pm 0,05$ & 0,50 a 5,00 \\
\hline Oleico (C18:1) & $75,30 \pm 0,66$ & $72,05 \pm 1,78$ & 55,00 a 83,00 \\
\hline Linoleico (C18:2) & $10,35 \pm 0,57$ & $11,35 \pm 0,72$ & 2,50 a 21,00 \\
\hline Linolênico (C18:3) & $0,77 \pm 0,01$ & nd & $<1,00$ \\
\hline
\end{tabular}

${ }^{*} \mathrm{C}$ x:y; $\mathrm{x}=$ número de carbonos; $\mathrm{y}=$ número de duplas ligações; ${ }^{*}$ Valores obtidos nas normas do International Olive Council (COI/T.15/NC N. ${ }^{\circ}$ 3/Rev. 8) (IOOC, 2015). 
Extração de oleuropeína a partir de folhas de oliveira utilizando solvente hidroalcoólico

Coppa, C. F. S. C. et al.

Tabela 5. Tempos de indução obtidos no aparelho Rancimat para as amostras de óleos vegetais com e sem a adição dos extratos de folhas de oliveira.

\begin{tabular}{ccc} 
Amostras & Condição experimental $^{*}$ & Tempos indução (h) $^{\star *}$ \\
\hline Azeite extravirgem & 1 & $24,22 \pm 0,41^{\mathrm{B}}$ \\
& 2 & $27,15 \pm 1,14^{\mathrm{A}}$ \\
Azeite comum & 3 & $25,54 \pm 0,08^{\mathrm{BA}}$ \\
& 1 & $14,26 \pm 0,32^{\mathrm{D}}$ \\
& 2 & $16,52 \pm 0,37^{\mathrm{C}}$ \\
\hline
\end{tabular}

*(1) Sem a adição dos extratos de folhas de oliveira; (2) Com a adição de massa conhecida de extrato de folhas de oliveira; (3) Com a adição do dobro da massa de extrato utilizada em (2); ${ }^{\star \star}$ Médias seguidas por letra maiúscula iguais na mesma coluna não diferem entre si no nível de $5 \%$ de significância, pelo Teste de Duncan.

que os compostos formados no processo de oxidação sejam detectáveis (FRANKEL, 1980; GARCIA-MESA et al., 1993; HILL, 1994; GUTIÉRREZ ROSALES, 1989; LAUBLI; BRUTTEL, 1986).

Como pode ser observado na Tabela 5, o período de indução do azeite extravirgem foi maior do que o do azeite comum. De fato, o azeite de oliva extravirgem contém naturalmente compostos fenólicos extraídos do fruto durante a extração do azeite, os quais contribuem para a sua estabilidade oxidativa (KRICHENE et al., 2010). De acordo com os resultados mostrados na Tabela 5, a adição de extratos de folha de oliveira aumentou o tempo de indução tanto para o azeite extravirgem como para o comum. Contudo, a adição do dobro de extrato (condição 3) não trouxe vantagens para o aumento da estabilidade oxidativa, visto que os tempos de indução obtidos nesta condição não diferem estatisticamente dos valores obtidos na condição 2. Salta et al. (2007) avaliaram os períodos de indução de alguns óleos vegetais (girassol, palma e oliva) enriquecidos com extratos de folhas de oliveira. Os resultados mostraram que os períodos de indução antes e depois do enriquecimento foram, respectivamente: 1,3 e 2 horas (para o óleo de girassol); 17,5 e 21 horas para o óleo de palma, e 9 e 13,5 horas para o azeite de oliva. Jorge (2010) realizou análises de estabilidade oxidativa em diferentes marcas de azeites de oliva e encontrou valores dos tempos de indução variando de 9,04 a 42,44 horas. Krichene et al. (2010) estudaram a estabilidade oxidativa de algumas variedades de azeites de oliva virgem e o comportamento dos seus compostos antioxidantes naturais durante o armazenamento. Os tempos de indução das amostras de azeites virgens encontrados pelos autores variaram de 21,3 a 43,5 horas. Jimenez et al. (2011) avaliaram a estabilidade oxidativa em óleos de girassol, canola e soja enriquecidos com três tipos de extratos de folhas de oliveira: um extrato hidroalcoólico, um suco extraído pela prensagem das folhas e um extrato obtido com $\mathrm{CO}_{2}$ supercrítico. Os extratos foram adicionados às amostras de óleos que continham concentrações de polifenóis iguais $250 \mathrm{mg} \mathrm{GAE} / \mathrm{kg}$ de óleo e $630 \mathrm{mg}$ GAE/kg de óleo. Os autores concluíram que, para todos os óleos, os extratos obtidos por extração supercrítica proporcionaram o maior aumento dos períodos de indução, quando comparados com as amostras controle. Além disso, observou-se que os óleos com maiores concentrações iniciais de polifenóis possuem naturalmente uma maior resistência à oxidação, uma vez que os períodos de indução encontrados para as amostras que continham $630 \mathrm{mg} \mathrm{GAE} / \mathrm{kg}$ de óleo foram maiores do que os valores encontrados para as amostras com 250 mg GAE/kg de óleo.

\section{Conclusão}

Neste estudo, concluiu-se que é possível obter extratos com níveis significativos de oleuropeína utilizando solventes renováveis. Apesar de a maior quantidade de solvente ( $F O / S=1: 8)$ ter conduzido a um rendimento mais elevado de oleuropeína, um extrato mais concentrado no composto de interesse (oleuropeína) foi obtido utilizando-se a menor quantidade de solvente estudada ( $F O / S=1: 3$ ). Os resultados expressos neste trabalho também indicaram que a adição de extrato rico em oleuropeína pode ser positivo para o aumento da estabilidade oxidativa do azeite.

\section{Agradecimentos}

Os autores gostariam de agradecer a Capes, Fapesp e ao CNPq (308615/2016-6; 303797/2016-9) pelo apoio financeiro.

\section{Referências}

ACHAT, S.; TOMAO, V.; MADANI, K.; CHIBANE, M.; ELMAATAOUI, M.; DANGLES, O.; CHEMAT, F. Direct enrichment of olive oil in oleuropein by ultrasound-assisted maceration at laboratory and pilot plant scale. Ultrasonics Sonochemistry, v. 19, n. 4, p. 777-786, 2012. PMid:22281378. http://dx.doi.org/10.1016/j. ultsonch.2011.12.006.

ALTINYAY, C.; ALTUN, M. L. HPLC analysis of oleuropein in Olea Europaea L. Journal of Faculty of Pharmacy, v. 35, n. 1, p. 1-11, 2006.

AOUIDI, F.; DUPUY, N.; ARTAUD, J.; ROUSSOS, S.; MSALLEM, M.; GAIME, I. P.; HAMDI, M. Rapid quantitative determination 
Extração de oleuropeína a partir de folhas de oliveira utilizando solvente hidroalcoólico

Coppa, C. F. S. C. et al.

of oleuropein in olive leaves (Olea europaea) using mid-infrared spectroscopy combined with chemometric analyses. Industrial Crops and Products, v. 37, n. 1, p. 292-297, 2012. http://dx.doi. org/10.1016/j.indcrop.2011.12.024.

BILGIN, M.; SAHIN, S. Effects of geographical origin and extraction methods on total phenolic yield of olive tree (Olea europaea) leaves. Journal of the Taiwan Institute of Chemical, v. 44, n. 1, p. 8-12, 2013. http://dx.doi.org/10.1016/j.jtice.2012.08.008.

BRASIL. Ministério da Agricultura, Pecuária e Abastecimento - MAPA. Instrução Normativa n 1, de 30 de janeiro de 2012. Regulamento Técnico do azeite de oliva e do óleo de bagaço de oliva. Diário Oficial [da] República Federativa do Brasil, Brasília, DF, 1 de fev. 2012.

ERBAY, Z.; ICIER, F. Optimization of hot air drying of olive leaves using response surfasse methodology. Journal of Food Engineering, v. 91, n. 4, p. 533-541, 2009. http://dx. doi. org/10.1016/j.jfoodeng.2008.10.004.

FIRESTONE, D. (Ed.). Official methods and recommended practices of the AOCS. 5th ed. Champaign: AOCS. 1998. v. 2.

FRANKEL, E. N. Lipid oxidation. Progress in Lipid Research, v. 19, n. 1-2, p. 1-22, 1980. PMid:7232452. http://dx.doi. org/10.1016/0163-7827(80)90006-5.

GALANAKIS, C. M.; TORNBERG, E.; GEKAS, V. Recovery and preservation of phenols from olive waste in ethanolic extracts. Journal of Chemical Technology and Biotechnology, v. 85, n. 8, p. 1148-1155, 2010. http://dx.doi.org/10.1002/jctb.2413.

GARCIA-MESA, J. A.; LUQUE DE CASTRO, M. D.; VALCARCEL, $M$. Factors affecting the gravimetric determination of the oxidative stability of oils. Journal of the American Oil Chemists' Society, v. 70, n. 3, p. 245-247, 1993. http://dx.doi.org/10.1007/BF02545303.

GUTIÉRREZ ROSALES, F. Determinación de la estabilidad oxidativa de aceite de oliva vírgenes: comparación entre el método del oxígeno activo (A.O.M.) y el método Rancimat. Grasas y Aceites, v. 40, p. 1-5, 1989.

HILL, S. E. A comparison of modern instruments for the analysis of the oxidation stability of fats, oils and foods. Inform, v. 1, p. 104-109, 1994.

HORWITZ, W. (Ed.). Official methods of analysis of the Association of Official Analytical Chemists. 18th ed. Gaithersburg: AOAC, 2005a. Method 945.18.

HORWITZ, W. (Ed.). Official methods of analysis of the Association of Official Analytical Chemists. 18th ed. Gaithersburg: AOAC, 2005b. Method 963.15.

HORWITZ, W. (Ed.). Official methods of analysis of the Association of Official Analytical Chemists. 18th ed. Gaithersburg: AOAC, 2005c. Method 993.19.

HORWITZ, W. (Ed.). Official methods of analysis of the Association of Official Analytical Chemists. 18th ed. Gaithersburg: AOAC, 2005d. Method 945.15.
INTERNATIONAL OLIVE COUNCIL - IOOC. Trade standard applying to olive oils and olive-pomace oils. Madrid: IOOC, 2015. 17 p. COI/T.15/NC No 3/Rev. 8.

JAPÓN-LUJÁN, R.; LUQUE-RODRÍGUEZ, J. M.; LUQUE DE CASTRO, M. D. Dynamic ultrasound-assisted extraction of oleuropein and related biophenols from olive leaves. Journal of Chromatography A, v. 1108, n. 1, p. 76-82, 2006a. PMid:16442552. http://dx.doi.org/10.1016/j.chroma.2005.12.106.

JAPÓN-LUJÁN, R.; LUQUE-RODRÍGUEZ, J. M.; LUQUE DE CASTRO, M. D. Multivariate optimization of the microwaveassisted extraction of oleuropein and related biophenols from olive leaves. Analytical and Bioanalytical Chemistry, v. 385, n. 4, p. 753-759, 2006b. PMid:16741775. http://dx.doi.org/10.1007/ s00216-006-0419-0.

JIMENEZ, P.; MASSON, L.; BARRIGA, A.; CHÁVEZ, J.; ROBERT, P. Oxidative stability of oils containing olive leaf extracts obtained by pressure, supercritical and solvent-extraction. European Journal of Lipid Science and Technology, v. 113, n. 4, p. 497-505, 2011. http://dx.doi.org/10.1002/ejlt.201000445.

JORGE, R. O. Caracterização de azeites virgem extra "gourmet" varietais e "blends" comercializados no mercado do Rio Grande do Sul. 2010. 103 f. Tese (Doutorado)-Faculdade de Agronomia Eliseu Maciel, Universidade Federal de Pelotas, Pelotas, 2010.

KRICHENE, D.; ALLALOUT, A.; MANCEBO-CAMPOS, V.; SALVADOR, M. D.; ZARROUK, M.; FREGAPANE, G. Stability of virgin olive oil and behaviour of its natural antioxidants under medium temperature accelerated storage conditions. Food Chemistry, v. 121, n. 1, p. 171-177, 2010. http://dx.doi. org/10.1016/j.foodchem.2009.12.026.

LAUBLI, M. W.; BRUTTEL, P. A. Determination of the oxidative stability of fats and oils: comparison between the active oxygen method (AOCS Cd12 57) and the Rancimat method. Journal of the American Oil Chemists' Society, v. 63, n. 6, p. 792-795, 1986. http://dx.doi.org/10.1007/BF02541966.

LOZANO-SÁNCHEZ, J.; CASTRO-PUYANA, M.; MENDIOLA, J. A.; SEGURA-CARRETERO, A.; CIFUENTES, A.; IBÁÑEZ, E. Recovering bioactive compounds from olive oil filter cake by advanced extraction techniques. International Journal of Molecular Sciences, v. 15, n. 9, p. 16270-16283, 2014. PMid:25226536. http://dx.doi.org/10.3390/ijms150916270.

LUQUE DE CASTRO, M. D. L.; GARCIA-AYUSO, L. E. Soxhlet extraction of solid materials: an outdated technique with a promising innovative future. Analytica Chimica Acta, v. 369, n. 1-2, p. 1-10, 1998. http://dx.doi.org/10.1016/S0003-2670(98)00233-5.

LUQUE DE CASTRO, M. D. L.; PRIEGO-CAPOTE, F. P. Soxhlet extraction: past and present panacea. Journal of Chromatography A, v. 1217, n. 16, p. 2383-2389, 2010. PMid:19945707. http:// dx.doi.org/10.1016/j.chroma.2009.11.027.

MICOL, V.; CATURLA, N.; PÉREZ-FONS, L.; MÁS, V.; PÉREZ, L.; ESTEPA, A. The olive leaf extract exhibits antiviral activity against 
Extração de oleuropeína a partir de folhas de oliveira utilizando solvente hidroalcoólico

Coppa, C. F. S. C. et al.

viral haemorrhagic septcaemia rhabdovirus (VHSV). Antiviral Research, v. 66, n. 2-3, p. 129-136, 2005. PMid:15869811. http:// dx.doi.org/10.1016/j.antiviral.2005.02.005.

MKAOUAR, S.; BAHLOUL, N.; GELICUS, A.; ALLAF, K.; KECHAOU, $\mathrm{N}$. Instant controlled pressure drop texturing for intensifying ethanol solvent extraction of olive (Olea europaea) leaf polyphenols. Separation and Purification Technology, v. 145, p. 139-146, 2015. http://dx.doi.org/10.1016/j.seppur.2015.03.014.

MOSCA, M.; CUOMO, F.; LOPEZ, F.; CEGLIE, A. Role of emulsifier layer, antioxidants and radical initiators in the oxidation of olive oil-in-water emulsions. Food Research International, v. 50, n. 1 , p. 377-383, 2013. http://dx.doi.org/10.1016/j.foodres.2012.10.046.

MUSTAFA, A.; TURNER, C. Pressurized liquid extraction as a green approach in food and herbal plants extraction: a review. Analytica Chimica Acta, v. 703, n. 1, p. 8-18, 2011. PMid:21843670. http:// dx.doi.org/10.1016/j.aca.2011.07.018.

PACETTA, C. F. Estudos de diferentes metodologias para a obtenção de extratos de folhas de oliveira (Olea europaea) contendo oleuropeína. 2013. 82 f. Dissertação (Mestrado)Faculdade de Zootecnia e Engenharia de Alimentos, Universidade de São Paulo, Pirassununga, 2013.

PAQUOT, C. Standard methods for the analysis of oils, fats and derivatives. 6th ed. Oxford: Pergamon Press, 1979. Part 1, Sections I and II.

SAHIN, S.; BILGIN, M.; DRAMUR, M. U. Investigation of oleuropein content in olive leaf extract obtained by supercritical fluid extraction and soxhlet methods. Separation Science and Technology, v. 46, n. 11, p. 1829-1837, 2011. http://dx.doi.org/10.1080/01496 395.2011 .573519

SALTA, F. N.; MYLONA, A.; CHIOU, A.; ANDRIKOPOULOS, N. K. Oxidative stability of edible vegetable oils enriched in polyphenols with olive leaf extract. Food Science and Technology International, v. 13, n. 6, p. 413-421, 2007.

STAMATOPOULOS, K.; CHATZILAZAROU, A.; KATSOYANNOS, E. Optimization of multistage extraction of olive leaves for recovery of phenolic compounds at moderated temperatures and short extraction times. Foods, v. 3, n. 1, p. 66-81, 2014. http://dx.doi. org/10.3390/foods3010066

TAAMALLI, A.; ARRÁEZ-ROMÁN, D.; BARRAJÓN-CATALÁN, E.; RUIZ-TORRES, V.; PÉREZ-SÁNCHEZ, A.; HERRERO, M.; IBAÑEZ, E.; MICOL, V.; ZARROUK, M.; SEGURA-CARRETERO, A.; FERNÁNDEZ-GUTIÉRREZ, A. Use of advanced techniques for the extraction of phenolic compounds from Tunisian olive leaves: phenolic composition and cytotoxicity against human breast cancer cells. Food and Chemical Toxicology, v. 50, n. 6, p. 1817-1825, 2012. PMid:22433985. http://dx.doi.org/10.1016/j. fct.2012.02.090.

TABERA, J.; GUINDA, Á.; RUIZ-RODRÍGUEZ, A.; SEÑORÁNS, F. J.; IBÁÑEZ, E.; ALBI, T.; REGLERO, G. Countercurrent supercritical fluid extraction and fractionation of high-added value compounds from a hexane extract of olive leaves. Journal of Agricultural and Food Chemistry, v. 52, n. 15, p. 4774-4779, 2004. PMid:15264913. http://dx.doi.org/10.1021/jf049881+

TRIPOLI, E.; GIAMMANCO, M.; TABACCHI, G.; MAJO, D.; GIAMMANCO, S.; GUARDIA, M. The phenolic compounds of olive oil: structure, biological activity and beneficial effects on human health. Nutrition Research Reviews, v. 18, n. 1, p. 98-112, 2005. PMid:19079898. http://dx.doi.org/10.1079/NRR200495.

VISIOLI, F.; BELLOSTA, S.; GALLI, C. Oleuropein, the bitter principle of olives, enhances nitric oxide production by mouse macrophages. Life Sciences, v. 62, n. 6, p. 541-546, 1998. PMid:9464466. http://dx.doi.org/10.1016/S0024-3205(97)01150-8.

XIE, P.; HUANG, L.; ZHANG, C.; YOU, F.; ZHANG, Y. Reduced pressure extraction of oleuropein from olive leaves (Olea europaea L.) with ultrasound assistance. Food and Bioproducts Processing, v. 93, p. 29-38, 2013. http://dx.doi.org/10.1016/j. fbp.2013.10.004.

XYNOS, N.; PAPAEFSTATHIOU, G.; PSYCHIS, M.; ARGYROPOULOU, A.; ALIGIANNIS, N.; SKALTSOUNIS, A. Development of a green extraction procedure with super/subcritical fluids to produce extracts enriched in oleuropein from olive leaves. The Journal of Supercritical Fluids, v. 67, p. 89-93, 2012. http://dx.doi. org/10.1016/j.supflu.2012.03.014. 